\title{
Braiding a molecular knot with eight crossings
}

DOI:

10.1126/science.aal1619

\section{Document Version}

Accepted author manuscript

Link to publication record in Manchester Research Explorer

\section{Citation for published version (APA):}

Danon, J., Krüger, A., Leigh, D., Lemonnier, J-F., Stephens, A., Vitorica-Yrezabal, I., \& Woltering, S. (2017). Braiding a molecular knot with eight crossings. Science, 355(6321), 159-162.

https://doi.org/10.1126/science.aal1619

\section{Published in:}

Science

\section{Citing this paper}

Please note that where the full-text provided on Manchester Research Explorer is the Author Accepted Manuscript or Proof version this may differ from the final Published version. If citing, it is advised that you check and use the publisher's definitive version.

\section{General rights}

Copyright and moral rights for the publications made accessible in the Research Explorer are retained by the authors and/or other copyright owners and it is a condition of accessing publications that users recognise and abide by the legal requirements associated with these rights.

\section{Takedown policy}

If you believe that this document breaches copyright please refer to the University of Manchester's Takedown Procedures [http://man.ac.uk/04Y6Bo] or contact uml.scholarlycommunications@manchester.ac.uk providing relevant details, so we can investigate your claim.

\section{OPEN ACCESS}




\title{
Braiding a molecular knot with eight crossings
}

\author{
Jonathan J. Danon, Anneke Krüger, David A. Leigh, * Jean-François Lemonnier, Alexander J.
} Stephens, Iñigo J. Vitorica-Yrezabal, Steffen L. Woltering

School of Chemistry, University of Manchester, Oxford Road, Manchester, M13 9PL, UK

*Correspondence to: david.leigh@manchester.ac.uk

\begin{abstract}
Knots may ultimately prove just as versatile and useful at the nanoscale as at the macroscale. However, the lack of synthetic routes to all but the simplest molecular knots currently prevents systematic investigation of the influence of knotting at the molecular level. Here we demonstrate that it is possible to braid three ligand strands. Octahedral Fe(II) ions control the relative positions of the three strands at each crossing point in a circular triple helicate, while structural constraints on the ligands determine the braiding connections. This approach enables two-step assembly of a molecular $8_{19}$ knot featuring eight non-alternating crossings in a 192-atom ( $\sim 20 \mathrm{~nm}$ long) closed loop. The resolved metal-free $8_{19}$ knot enantiomers have pronounced features in their circular dichroism spectra resulting solely from topological chirality.
\end{abstract}

One Sentence Summary: The braiding of ligand strands is used to self-assemble the most tightly knotted physical structure known, a molecular $8_{19}$ knot featuring eight non-alternating crossings in a 192-atom ( $20 \mathrm{~nm}$ long) closed loop.

Knots (1) form spontaneously in flexible polymer chains (2) and are found in circular DNA (3) and $\sim 1 \%$ of proteins in the protein data bank (PDB) (4). To date only three non-trivial knot topologies (trefoil, figure-eight and pentafoil) (5-16) out of more than six billion $(17,18)$ known prime knots have been synthesized with small molecules. Most of the molecular knots isolated to date have been unanticipated reaction products $(6,7,10,12,14)$, but a few designed strategies for the construction of simple small-molecule knots have been successfully developed, including the use of linear (5) and cyclic (11) double helicates that twist two ligand strands about each other several times (13). Every knot can be formed by braiding (19) strings and joining their ends together (Fig. 1) (20). However, the number of strings required for a particular knot depends on its topology. Twisting two strings about each other can generate only four of the 84 prime knots with up to nine crossings, whilst having three strings to braid makes nearly a third of such knots accessible (21). Sauvage synthesized the first molecular trefoil knot (5), and a Solomon link (22), using linear double helicates in which two ligand strands are twisted about one another to generate the required number of crossings (three and four, respectively) followed by joining of the termini of each strand along the length of the helicate (Fig. 1a). Recently, a Solomon link (23), pentafoil knots $(11,24)$ (five crossings) and a Star of David catenane (25) (six crossings) were prepared using double helicates that are cyclic, which reduces the distances needed to join 
the strands into closed loops (Fig. 1b). These circular helicates use Fe(II) ions to entwine two ligand strands: two bipyridine (bipy) chelating groups coordinated to the same metal ion are connected in the knot-forming reaction to form a strand that crosses that of the third bipy unit bound to the metal ion. However, the octahedral coordination geometry of these metal ions could, in principle, be used to position three bipy-containing strands with respect to each other. The key is to design ligands so that connections can only be made to bipy groups that are coordinated to adjacent metal ions. In this way the octahedral Fe(II) metal ions can control the relative position of three ligand strands at each crossing point (Fig. 1c).

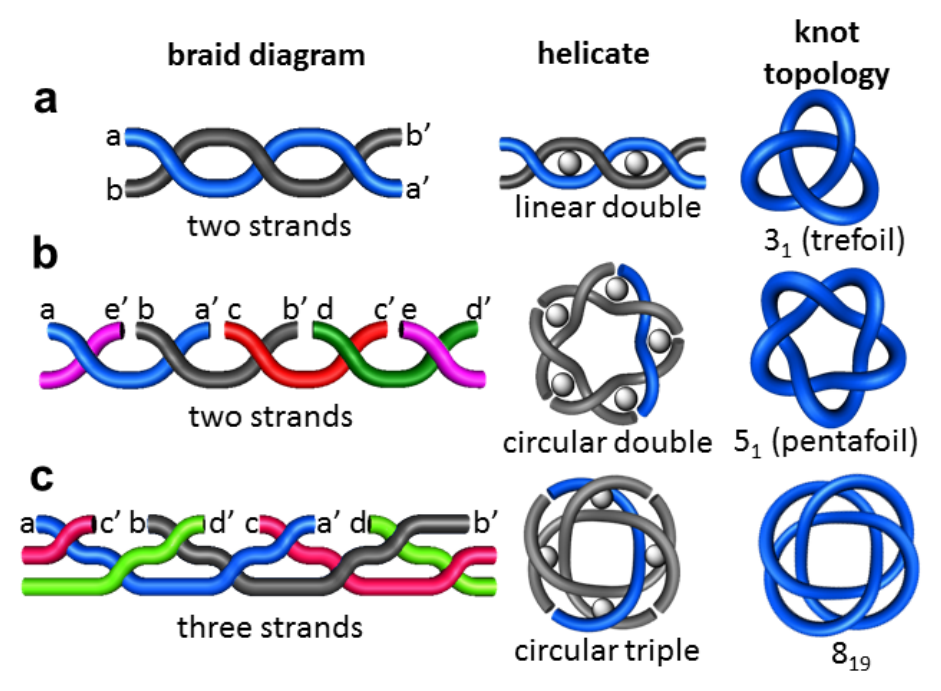

Fig. 1. Tying molecular knots by twisting and braiding ligand strands. a Sauvage's strategy to trefoil knots assembled from linear double helicates. Two metal ions control three crossings, and the knot is obtained by closing the oriented endgroups a to $b^{\prime}$ and $b$ to $a^{\prime}$. b Pentafoil knots have been derived from cyclic pentameric double helicates. Five metal ions control five crossings points for five building blocks assembled into a circular double helix through connections a to d', b to e', c to $\mathrm{a}^{\prime}, \mathrm{d}$ to $\mathrm{b}^{\prime}$ and e to c'. c An $8_{19}$ knot can be synthesized from a cyclic tetrameric triple helicate. Four metal ions control eight crossing points for four building blocks assembled into a circular triple helix with connections made from $\mathrm{a}$ to $\mathrm{b}^{\prime}, \mathrm{b}$ to $c^{\prime}$, $c$ to $d^{\prime}$ and $d$ to $a^{\prime}$. A feature of circular helicates is that the building blocks can be joined at different points along the braid to generate the desired number and sequence of crossings, rather than only at the braid ends.

The $8_{19}$ knot (Alexander-Briggs notation: the main number denotes the number of crossings; the subscript differentiates the knot from others with the same number of crossings (20)) is one of 21 prime knots with eight crossings (20). Along with the $8_{20}$ and $8_{21}$ knots it is the simplest nonalternating knot and is absent from early knot tables (26) as it was not immediately recognized (27) (still less proven (28)) that not all knots can be written in a form that alternates crossings over-under around the closed loop. The $8_{19}$ knot is the $\mathrm{T}(3,4)$ torus knot, meaning that it can be represented by a closed loop that wraps around a torus (doughnut shape) three times longitudinally and four times meridionally without crossing itself (fig. S18) (20). Its most symmetrical form suggests a strategy to access it through a three-stranded braid using a four-fold repeat motif (Fig. 1c). Indeed, recent simulations showed an $8_{19}$ knot to be a favored structure in the theoretical assembly of four rigid helical building blocks with sticky ends (29). We envisaged employing a tetrameric circular triple helicate (30) within which each of four metal ions binds to bipy units from three different ligand strands. Rigid extensions from the bipy groups at both ends 
of each strand ensure that the terminal alkene groups are positioned such that they can only undergo olefin metathesis to groups coordinated to adjacent $\mathrm{Fe}(\mathrm{II})$ ions, producing the connections required to form an $8_{19}$ knot (Fig. 2).
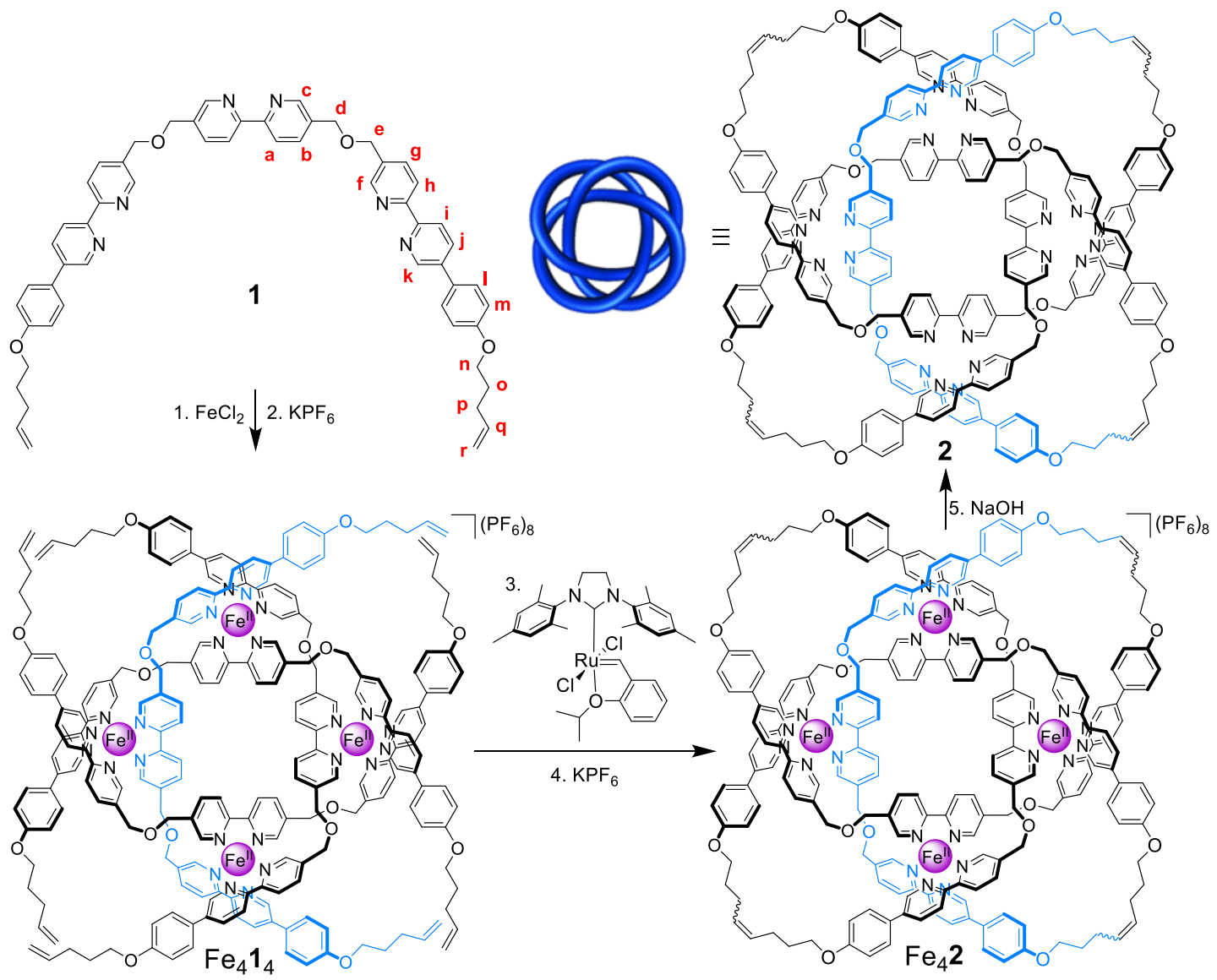

Fig. 2. Synthesis of a molecular $8_{19}$ knot, 2. Reaction conditions: 1.1 (1.0 equiv.), $\mathrm{FeCl}_{2}(1.0$ equiv.), $N, N$-dimethylformamide (DMF), $130{ }^{\circ} \mathrm{C}, 24$ h. $2 . \mathrm{KPF}_{6}, \mathrm{MeOH}, 60 \%$ (two steps). 3 . Hoveyda-Grubbs $2^{\text {nd }}$ generation catalyst ( $25 \mathrm{~mol} \%$ per olefin metathesis reaction), $\mathrm{MeNO}_{2} / 1,2$-dichloroethane $1: 1,60{ }^{\circ} \mathrm{C}, 24 \mathrm{~h}$. 4. $\mathrm{KPF}_{6}, \mathrm{H}_{2} \mathrm{O}, 62 \%$ (two steps). 5. $\mathrm{NaOH}_{\text {(aq) }}(1 \mathrm{M}) / \mathrm{MeCN} 1: 1,70{ }^{\circ} \mathrm{C}, 30 \mathrm{~min}, 38 \%$.

Ligand strand 1 and $\mathrm{FeCl}_{2}$ were heated at $130{ }^{\circ} \mathrm{C}$ in $\mathrm{N}, \mathrm{N}$-dimethylformamide (DMF) for $24 \mathrm{~h}$ (Fig. 2, step 1). Subsequent treatment with methanolic $\mathrm{KPF}_{6}$ afforded a red precipitate, determined by electrospray ionization mass spectrometry (ESI-MS) to be a tetrameric complex $\left[\mathrm{Fe}_{4} \mathbf{1}_{4}\right]\left(\mathrm{PF}_{6}\right)_{8}$ (Fig. 2, step 2). Carrying out the assembly process in solvents other than DMF (e.g. ethylene glycol or dimethylsulfoxide (DMSO)) produced substantial quantities of a trimer, $\left[\mathrm{Fe}_{3} \mathbf{1}_{3}\right]\left(\mathrm{PF}_{6}\right)_{6}$, presumed to a linear triple helicate (25), which could not easily be separated from the tetramer. The ${ }^{1} \mathrm{H}$ NMR spectrum of $\left[\mathrm{Fe}_{4} \mathbf{1}_{4}\right]\left(\mathrm{PF}_{6}\right)_{8}$ (Fig. $3 \mathrm{~b}$ ) showed all four ligands to be in the same symmetric environment, only possible with a cyclic arrangement of ligands, with the diastereotopic splitting of protons $\mathrm{H}_{\mathrm{d}}$ and $\mathrm{H}_{\mathrm{e}}$ indicative of a helical conformation.

Tetrameric complex $\left[\mathrm{Fe}_{4} \mathbf{1}_{4}\right]\left(\mathrm{PF}_{6}\right)_{8}$ was treated with the Hoveyda-Grubbs second generation catalyst (31) at $60{ }^{\circ} \mathrm{C}$ in nitromethane/1,2-dichloroethane (1:1) (Fig. 2, step 3). After $24 \mathrm{~h}$ the reaction was quenched with ethyl vinyl ether and the product precipitated with aqueous $\mathrm{KPF}_{6}$ in 
an effort to confer anion uniformity and to remove catalyst residues (Fig. 2, step 4), furnishing $\left[\mathrm{Fe}_{4} 2\right]\left(\mathrm{PF}_{6}\right)_{8}$ in $62 \%$ yield over two steps. ESI-MS was consistent with the loss of four ethene molecules from $\left[\mathrm{Fe}_{4} \mathbf{1}_{4}\right]\left(\mathrm{PF}_{6}\right)_{8}$ (fig. S7) and ${ }^{1} \mathrm{H}$ NMR spectroscopy confirmed the loss of the terminal olefin signals from the precursor complex (Fig. 3c). In some experiments ESI-MS indicated incomplete anion exchange and contamination of the product with a small amount of $\left[\mathrm{Fe}_{4} 2\right]\left(\mathrm{PF}_{6}\right)_{7} \mathrm{Cl}$ (fig. S13).

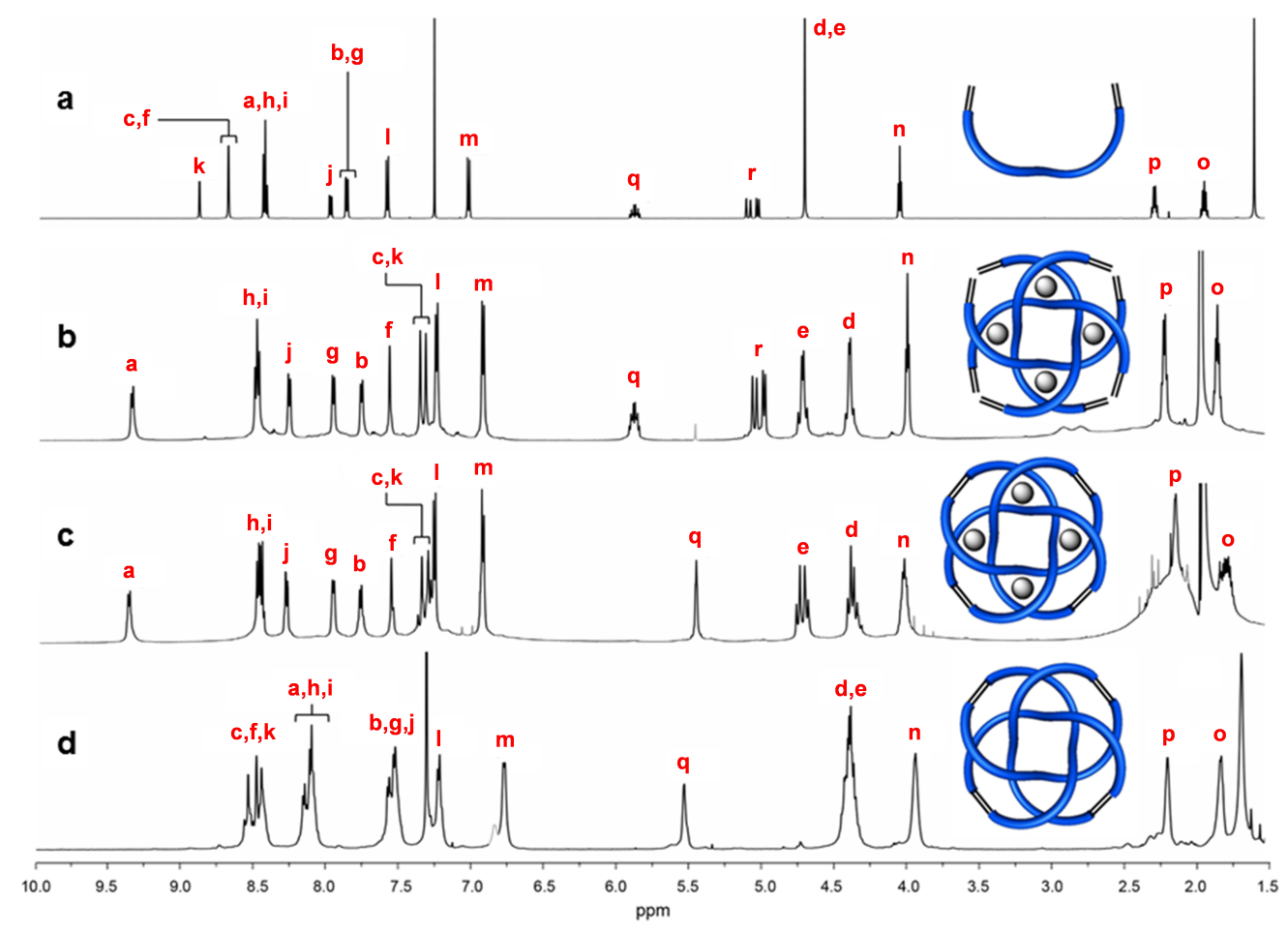

Fig. 3. ${ }^{1} \mathrm{H}$ NMR spectra (600 MHz, $\left.298 \mathrm{~K}\right)$ of molecular $8_{19}$ knot 2 and its complexes and precursors. a Ligand strand $\mathbf{1}$ (solvent $\left.\mathrm{CDCl}_{3}\right)$; b tetrameric circular helicate $\left[\mathrm{Fe}_{4} \mathbf{1}_{4}\right]\left(\mathrm{PF}_{6}\right)_{8}$ (solvent $\left.\mathrm{CD}_{3} \mathrm{CN}\right)$; c $8_{19}$ knot complex $\left[\mathrm{Fe}_{4} 2\right]\left(\mathrm{PF}_{6}\right)_{8}$ (solvent $\mathrm{CD}_{3} \mathrm{CN}$ ); d metal-free $8_{19}$ knot 2 (solvent $\mathrm{CDCl}_{3}$ ). The lettering corresponds to the proton labelling in Fig. 2. Full spectral assignments are given in Supplementary Material, Section 2.

Slow evaporation of a saturated acetonitrile solution of the $\mathrm{Fe}_{4} 2$ knot complex produced red needles over several days suitable for single crystal X-ray diffraction. The solid state structure confirms the topology and $D_{4}$-symmetry of the molecular $8_{19}$ knot (Fig. 4, Supplementary Material Section 6 and movie S1). The organic ligand weaves a continuous 192-atom path passing each of the four co-planar iron centers three times to form a circular triple helicate closed loop with eight non-alternating crossings. Both $E$ - and $Z$-olefins are present in the chain, with some disorder, in approximately a $1: 1$ ratio. Each $\mathrm{Fe}(\mathrm{II})$ ion is bound to three bipy groups with the Fe-N distances in the 1.92 to $2.02 \AA$ range typical (32) for $\mathrm{Fe}(\text { bipy })_{3}{ }^{2+}$ complexes. The metal ion octahedral coordination geometry is slightly distorted by the constraints of the tightly knotted ligand, with $\mathrm{N}-\mathrm{Fe}-\mathrm{N}$ angles within each bipyridyl moiety of ca. $81^{\circ}$. The bipyridine groups define a cavity of diameter 3.30(2) $\AA$ (compared to 3.7(1) $\AA$ for a related Solomon link (33)). At the center, a chloride anion is bound by eight $\mathrm{CH}^{\cdots} \mathrm{Cl}$ hydrogen bonds. Although the presence of the chloride ion is somewhat surprising given the anion exchange reaction with $\mathrm{KPF}_{6}$, it is 
reminiscent of the solid state structures of anion template pentafoil knots $(11,24)$ and, as with those knots, we found the $\mathrm{Fe}_{4} 2$ knot complex to bind a single chloride anion strongly in solution $\left(K_{\mathrm{a}}=2.6 \pm 0.1 \times 10^{8} \mathrm{M}^{-1}\right.$ in MeCN, $298 \mathrm{~K}$; Supplementary Material Section 4).
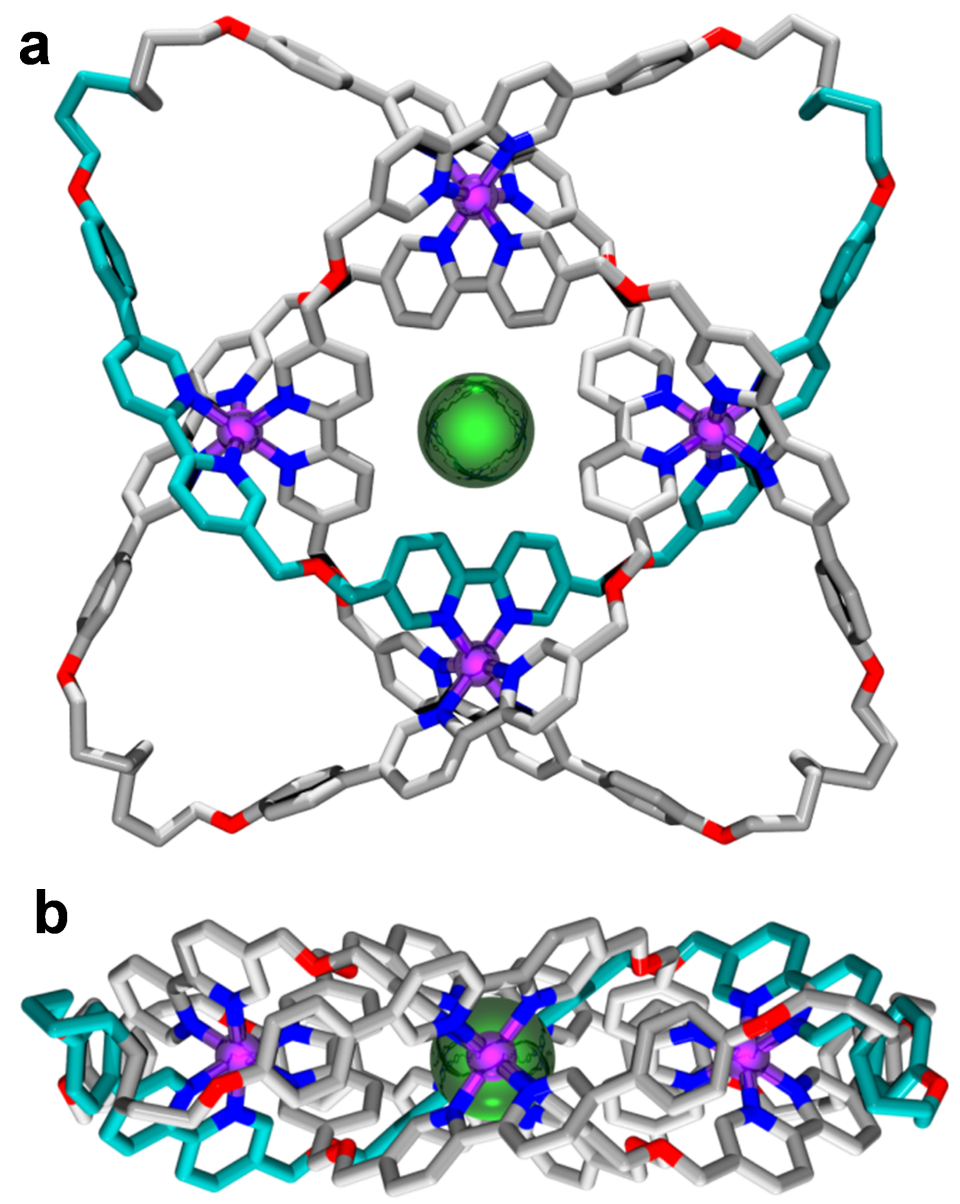


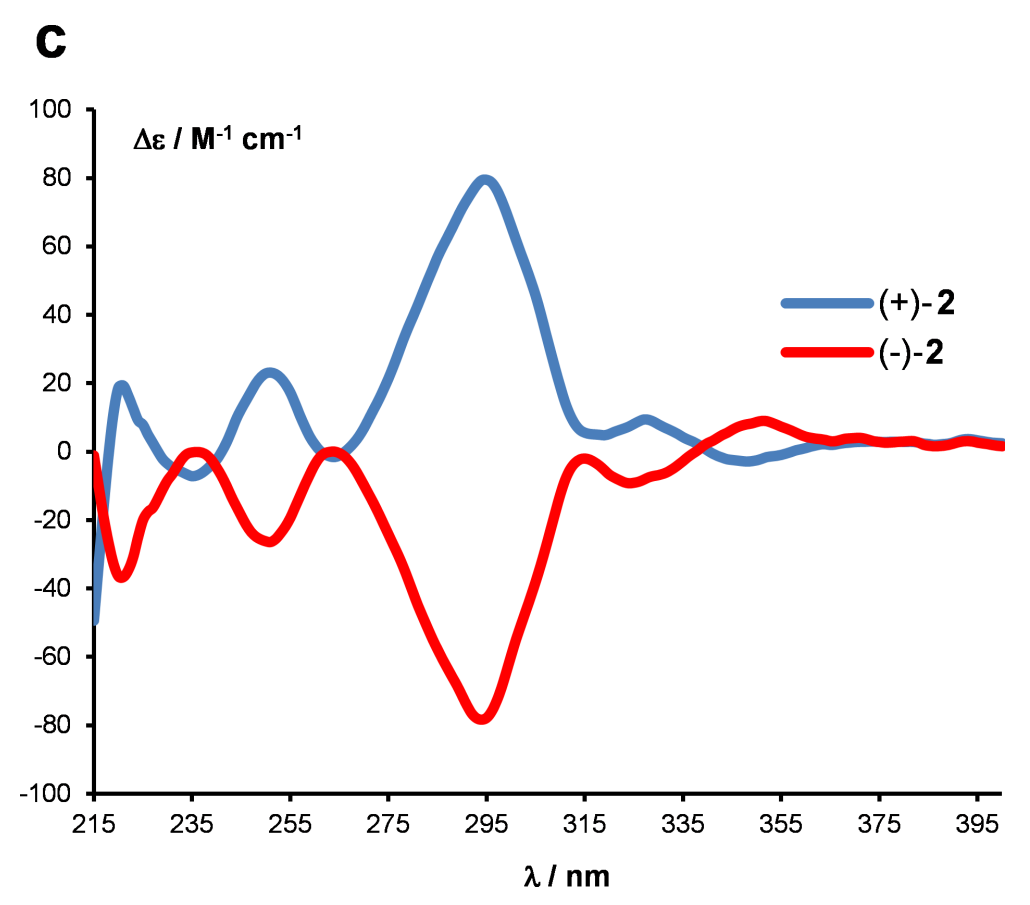

Fig. 4. X-Ray crystal structure of molecular $8_{19}$ knot complex $\left[\mathrm{Fe}_{4} 2\right]\left(\mathrm{PF}_{6}\right)_{7} \mathrm{Cl}$ and circular dichroism (CD) spectra of each mirror image form of metal-free $8_{19}$ knot ligand 2 . a X-Ray structure viewed perpendicular to the plane of the four Fe(II) ions. b Side view, in the plane of the four Fe(II) ions. C atoms are light grey (turquoise in one repeat unit of the knot); $\mathrm{N}$, blue; $\mathrm{O}$, red; $\mathrm{Fe}$, purple. $\mathrm{PF}_{6}{ }^{-}$anions and hydrogen atoms omitted for clarity. The iron(II) centers in each molecular knot have the same coordination stereochemistry $(\Lambda$ or $\Delta)$. Both enantiomers are present in each unit cell; the all- $\Lambda$ enantiomer is shown here. c CD spectra of $8_{19}$ knot enantiomers (+)-2 (blue) and (-)-2 (red, 90\% ee) in $\mathrm{CH}_{2} \mathrm{Cl}_{2}\left(1.76 \times 10^{-4} \mathrm{M}\right)$ at $298 \mathrm{~K}$.

Treatment of an acetonitrile solution of $\left[\mathrm{Fe}_{4} 2\right]\left(\mathrm{PF}_{6}\right)_{8}$ with $\mathrm{NaOH}(1 \mathrm{M})$ at $70{ }^{\circ} \mathrm{C}$ for 30 min. afforded the demetallated $8_{19}$ knot 2 in 38\% yield (Fig. 2, step 5). Matrix-assisted laser desorption/ionization mass spectrometry (MALDI-MS) gave an isotope distribution for the $[2 \cdot \mathrm{Na}]^{+}$molecular ion that matched the theoretical pattern and values (fig. S10). The ${ }^{1} \mathrm{H}$ NMR spectrum of 2 (Fig. 3d) is relatively broad in comparison to both the metallated knot $\left[\mathrm{Fe}_{4} 2\right]\left(\mathrm{PF}_{6}\right)_{8}$ (Fig. 3c) and building block 1 (Fig. 3a). Molecular modelling and variable temperature ${ }^{1} \mathrm{H}$ NMR (fig. S16) suggest 2 does not exist in a single well-defined conformation, and the broad features of the ${ }^{1} \mathrm{H}$ NMR spectrum are likely a consequence of reptation (the thermal motion of long, entangled, polymer chains (34)) as the 192-atom-long knot backbone's motion is restricted as it passes through tight loops and traverses crossings. Furthermore, most of the signals in the ${ }^{1} \mathrm{H}$ NMR spectrum of $\mathbf{2}$ (Fig. 3d) are shielded with respect to that of building block $\mathbf{1}$ (Fig. 3a), a reflection of the compact structure of the knot bringing each region of the loop into close proximity with aromatic rings during reptation.

The $8_{19}$ knot is intrinsically chiral by virtue of its topology. One enantiomer, (+)-2 (sign determined by optical rotation), could be isolated by chiral high performance liquid chromatography (HPLC) (Supplementary Material Section 3) and a sample of the other enantiomer obtained in highly enriched form ((-)-2, 90\% enantiomeric excess (ee)) (35). The mirror-image 819 knots have circular dichroism (CD) spectra of equal and opposite shape and 
sign (Fig. 4c) $(35,36)$. Despite the knots possessing no elements of Euclidean chirality, several features of the CD spectra (particularly the maxima/minima at 221, 250, 294, 327 and $351 \mathrm{~nm}$ ), show that the chiral environment is well expressed despite the dynamics of the closed loop and the absence of well-defined conformations, presumably also a result of the tightness of the knotting.

The braiding of ligand strands should enable the synthesis of many more molecular knots (and links $(25,37)$ ), of greater complexity, than has previously been possible (fig. S19). The inherent chirality of many knots, and the tightness of the knotting possible through this synthetic approach, may prove useful when investigating applications of knotting in molecular tools $(24$, $33,38)$ and materials $(39,40)$.

References and Notes:

1. $\quad$ N. C. H. Lim, S. E. Jackson. Molecular knots in biology and chemistry. J. Phys.: Condens. Matter 27, 354101 (2015).

2. M. D. Frank-Kamenetskii, A. V. Lukashin, A. V. Vologodskii. Statistical mechanics and topology of polymer chains. Nature 258, 398-402 (1975).

3. S. A. Wasserman, N. R. Cozzarelli. Biochemical topology: applications to DNA recombination and replication. Science 232, 951-960 (1986).

4. J. I. Sułkowska, E. J. Rawdon, K. C. Millett, J. N. Onuchic, A. Stasiak. Conservation of complex knotting and slipknotting patterns in proteins. Proc. Natl. Acad. Sci. U.S.A. 109, E1715-E1723 (2012).

5. C. O. Dietrich-Buchecker, J.-P. Sauvage. A synthetic molecular trefoil knot. Angew. Chem., Int. Ed. Engl. 28, 189-192 (1989).

6. O. Safarowsky, M. Nieger, R. Fröhlich, F. Vögtle. A molecular knot with twelve amide groups - One-step synthesis, crystal structure, chirality. Angew. Chem., Int. Ed. 39, 1616-1618 (2000).

7. M. Feigel, R. Ladberg, S. Engels, R. Herbst-Irmer, R. Fröhlich. A trefoil knot made of amino acids and steroids. Angew. Chem., Int. Ed. 45, 5698-5702 (2006).

8. J. Guo, P. C. Mayers, G. A. Breault, C. A. Hunter. Synthesis of a molecular trefoil knot by folding and closing on an octahedral coordination template. Nat. Chem. 2, 218-222 (2010).

9. P. E. Barran, H. L. Cole, S. M. Goldup, D. A. Leigh, P. R. McGonigal, M. D. Symes, J. Wu, M. Zengerle. Active-metal template synthesis of a molecular trefoil knot. Angew. Chem., Int. Ed. 50, 12280-12284 (2011).

10. N. Ponnuswamy, F. B. L. Cougnon, J. M. Clough, G. D. Pantoș, J. K. M. Sanders. Discovery of an organic trefoil knot. Science 338, 783-785 (2012).

11. J.-F. Ayme, J. E. Beves, D. A. Leigh, R. T. McBurney, K. Rissanen, D. Schultz. A synthetic molecular pentafoil knot. Nat. Chem. 4, 15-20 (2012).

12. T. Prakasam, M. Lusi, M. Elhabiri, C. Platas-Iglesias, J.-C. Olsen, Z. Asfari, S. Cianférani-Sanglier, F. Debaene, L. J. Charbonnière, A. Trabolsi. Simultaneous self-assembly of a [2]catenane, a trefoil knot, and a Solomon link from a simple pair of ligands. Angew. Chem., Int. Ed. 52, 9956-9960 (2013). 
13. J.-F. Ayme, J. E. Beves, C. J. Campbell, D. A. Leigh. Template synthesis of molecular knots. Chem. Soc. Rev. 42, 1700-1712 (2013).

14. N. Ponnuswamy, F. B. L. Cougnon, G. D. Pantoș, J. K. M. Sanders. Homochiral and meso figure eight knots and a Solomon link. J. Am. Chem. Soc. 136, 8243-8251 (2014).

15. J.-F. Ayme, G. Gil-Ramírez, D. A. Leigh, J.-F. Lemonnier, A. Markevicius, C. A. Muryn, G. Zhang. Lanthanide template synthesis of a molecular trefoil knot. J. Am. Chem. Soc. 136, 13142-13145 (2014).

16. G. Gil-Ramírez, S. Hoekman, M. O. Kitching, D. A. Leigh, I. J. Vitorica-Yrezabal, G. Zhang. Tying a molecular overhand knot of single handedness and asymmetric catalysis with the corresponding pseudo- $D_{3}$-symmetric trefoil knot. J. Am. Chem. Soc. 138, 13159-13162 (2016).

17. J. Hoste in Handbook of Knot Theory (Eds.: W. Menasco, M. Thistlethwaite,), Elsevier, Amsterdam, 2005, pp. 209-232.

18. E. E. Fenlon. Open problems in chemical topology. Eur. J. Org. Chem. 5023-5035 (2008).

19. T. Ciengshin, R. Sha, N. C. Seeman. Automatic molecular weaving prototyped by using single-stranded DNA. Angew. Chem., Int. Ed. 50, 4419-4422 (2011).

20. C. C. Adams. The Knot Book; Freeman: New York, 1994.

21. V. F. R. Jones. Hecke algebra representations of braid groups and link polynomials. Ann. Math. 126, 335-388 (1987).

22. J.-F. Nierengarten, C. O. Dietrich-Buchecker, J.-P. Sauvage. Synthesis of a doubly interlocked [2]-catenane. J. Am. Chem. Soc. 116, 375-376 (1994).

23. J. E. Beves, C. J. Campbell, D. A. Leigh, R. G. Pritchard. Tetrameric cyclic double helicates as a scaffold for a molecular Solomon link. Angew. Chem., Int. Ed. 52, 6464-6467 (2013).

24. V. Marcos, A. J. Stephens, J. Jaramillo-Garcia, A. L. Nussbaumer, S. L. Woltering, A. Valero, J.-F. Lemonnier, I. J. Vitorica-Yrezabal, D. A. Leigh. Allosteric initiation and regulation of catalysis with a molecular knot. Science 352, 1555-1559 (2016).

25. D. A. Leigh, R. G. Pritchard, A. J. Stephens. A Star of David catenane. Nat. Chem. 6, 978-982 (2014).

26. P. G. Tait. On knots II. Trans. Roy. Soc. Edinburgh, 32, 327-342 (1883-1884).

27. C. N. Little. XVIII.-Non-alternate \pm knots, of orders eight and nine. Trans. Roy. Soc. Edinburgh, 35, 663-664 (1889).

28. K. Murasugi. On alternating knots. Osaka Math. J. 12, 277-303 (1960).

29. G. Polles, D. Marenduzzo, E. Orlandini, C. Micheletti. Self-assembling knots of controlled topology by designing the geometry of patchy templates. Nat. Comm. 6, 6423 (2015).

30. B. Hasenknopf, J.-M. Lehn, N. Boumediene, A. Dupont-Gervais, A. Van Dorsselaer, B. Kneisel, D. Fenske. Self-assembly of tetra- and hexanuclear circular helicates. J. Am. Chem. Soc. 119, 10956-10962 (1997). 
31. S. B. Garber, J. S. Kingsbury, B. L. Gray, A. H. Hoveyda. Efficient and recyclable monomeric and dendritic Ru-based metathesis catalysts. J. Am. Chem. Soc. 122, 8168-8179 (2000).

32. M. E. García Posse, M. A. Juri, P. J. Aymonino, O. E. Piro, H. A. Negri, E. E. Castellano. Synthesis, crystal and molecular structure, and spectroscopic properties of tris(2,2'bipyridyl)iron(II) nitroprusside tetrahydrate, $\left[\mathrm{Fe}(\mathrm{bpy})_{3}\right]\left[\mathrm{Fe}(\mathrm{CN})_{5} \mathrm{NO}\right] \bullet 4 \mathrm{H}_{2} \mathrm{O}$. Inorg. Chem. 23, 948-952 (1984).

33. J.-F. Ayme, J. E. Beves, C. J. Campbell, G. Gil-Ramírez, D. A. Leigh, A. J. Stephens. Strong and selective anion binding within the central cavity of molecular knots and links. J. Am. Chem. Soc. 137, 9812-9815 (2015).

34. P. G. De Gennes. Reptation of a polymer chain in the presence of fixed obstacles. $J$. Chem. Phys. 55, 572-579 (1971).

35. F. Vögtle, A. Hünten E. Vogel, S. Buschbeck, O. Safarowsky, J. Recker, A.-H. Parham, M. Knott, W. M. Müller, U. Müller, Y. Okamoto, T. Kubota, W. Lindner, E. Francotte, S. Grimme. Novel amide-based molecular knots: Complete enantiomeric separation, chiroptical properties, and absolute configuration. Angew. Chem., Int. Ed. 40, 2468-2471 (2001).

36. G. Rapenne, C. Dietrich-Buchecker, J.-P. Sauvage. Resolution of a molecular trefoil knot. J. Am. Chem. Soc. 118, 10932-10933 (1996).

37. K. S. Chichak, S. J. Cantrill, A. R. Pease, S.-H. Chiu, G. W. V. Cave, J. L. Atwood, J. F. Stoddart. Molecular Borromean rings. Science 304, 1308-1312 (2004).

38. R. A. Bilbeisi，T. Prakasam, M. Lusi，R. El Khoury, C. Platas-Iglesias, L. J. Charbonnière, J.-C. Olsen, M. Elhabiri, A. Trabolsi. [C-H'"anion] interactions mediate the templation and anion binding properties of topologically non-trivial metal-organic structures in aqueous solutions. Chem. Sci. 7, 2524-2531 (2016).

39. A. M. Saitta, P. D. Soper, E. Wasserman, M. L. Klein. Influence of a knot on the strength of a polymer strand. Nature 399, 46-48 (1999).

40. Y. Liu, Y. Ma, Y. Zhao, X. Sun, F. Gándara, H. Furukawa, Z. Liu, H. Zhu, C. Zhu, K. Suenaga, P. Oleynikov, A. S. Alshammari, X. Zhang, O. Terasaki, O. M. Yaghi. Weaving of organic threads into a crystalline covalent organic framework. Science 351, 365-369 (2016).

41. K. P. Divya, S. Sreejith, B. Balakrishna, P. Jayamurthy, P. Anees, A. Ajayaghosh A Zn ${ }^{2+}-$ specific fluorescent molecular probe for the selective detection of endogenous cyanide in biorelevant samples Chem. Commun. 46, 6069-6071 (2010).

42. M. van den Heuvel, T. A. van der Berg, R. M. Kellogg, C. T. Choma, B. L. Feringa Synthesis of a non-heme template for attaching four peptides: an approach to artificial iron(II)containing peroxidases J. Org. Chem. 69, 250-262 (2004).

43. G. M. Sheldrick, SADABS, University of Göttingen, 1995, Empirical absorption correction program based upon the method of Blessing.

44. R. H. Blessing An empirical correction for absorption anisotropy Acta Crystallogr. A51, 33-38 (1995).

45. G. M. Sheldrick A short history of SHELX Acta Crystallogr. A64, 112-122 (2008). 
46. O. V. Dolomanov, L. J. Bourhis, R. J. Gildea, J. A. K. Howard, H. Puschmann OLEX2: a complete structure solution, refinement and analysis program J. Appl. Cryst. 42, 339-341 (2009).

47. PLATON, A Multipurpose Crystallographic Tool (Utrecht University, Utrecht, The Netherlands, 2008)

Acknowledgments We thank Dr Julia Collins (Australian Mathematical Sciences Institute, Melbourne, Australia) for advice on aspects of topology and non-alternating knots. This research was funded by the European Research Council (Advanced grant no. 339019). The authors thank the EPSRC National Mass Spectrometry Service Centre (Swansea, U.K.) for high-resolution mass spectrometry and the Diamond Light Source (UK) for synchrotron beamtime. CCDC1497422 contains the supplementary crystallographic data for this paper. These data can be

obtained free of charge via www.ccdc.cam.ac.uk/conts/retrieving.html (or from the Cambridge Crystallographic Data Centre, 12 Union Road, Cambridge CB21EZ, UK; fax: (+44)1223-336033; ordeposit@ccdc.cam.ac.uk).

\section{Supplementary Online Material:}

Materials and Methods

Figures S1-S18

Tables S1

Movie S1

References (41-47) 